\title{
ACOLHIMENTO INSTITUCIONAL: UMA GARANTIA DOS DIREITOS DA CRIANÇA?
}

\author{
INSTITUTIONAL FORE CARE: A GUARANTEE OF THE CHILD'S RIGHTS?
}

\author{
Maiara da Rocha Mascarenhas ${ }^{1}$ \\ Geórgia Patrícia Guimarães dos Santos ${ }^{2}$ \\ Ana Karla Batista Bezerra Zanella ${ }^{3}$ \\ Edilene Maria Vasconcelos Ribeiro ${ }^{4}$
}

\section{RESUMO}

Este artigo analisa a situação dos bebês recém-nascidos encaminhados da Maternidade Escola Assis Chateaubriand (MEAC), através do Conselho Tutelar, ao Acolhimento Institucional, em Fortaleza, Ceará. Por meio de levantamento de dados dos relatórios sociais da MEAC, no ano de 2012, identificamos que, em 43 desses relatórios encaminhados ao Conselho Tutelar, sete tiveram como desfecho a decisão pela institucionalização dos recém-nascidos. Utilizamos o método qualitativo descritivo de pesquisa, cujos instrumentais de coleta de dados foram a entrevista semiestruturada com os assistentes sociais das Unidades de Acolhimento e a pesquisa documental. Com efeito, constatamos que a maioria dessas crianças ainda permaneciam institucionalizadas devido à lentidão dos processos judiciais e à precariedade ou ausência das políticas sociais que viabilizam as condições necessárias às famílias para manterem suas crianças em seu convívio.

PALAVRAS-CHAVE: Institucionalização. Crianças. Família. ECA.

\begin{abstract}
This article analyzes newborn babie's situation directed from Maternidade Escola Assis Chateaubriand (MEAC), through Guardian Council, to Institutional Fore Care, in Fortaleza, Ceará. Through MEAC's social reports data collection, in 2012, we cognized that, in 43 of those reports reffered to the Guardian Council, seven resulted in the decision by the institutionalization of newborns. We used descriptive qualitative method of research, which instrumental data collection were semi-estructured interview with Fore Care Unit's social workers and documentary research. Actually, we realized that most of these children were still institutionalized due to the slowness of court proceedings and to the precariousness or absence of social policies that enable the necessary conditions for families keep their children living together with them.
\end{abstract}

KEYWORDS: Institutionalization. Children. Family. ECA.

\footnotetext{
${ }^{1}$ Assistente social especialista em Atenção Hospitalar à Saúde, modalidade de Residência Multiprofissional, pela Universidade Federal do Ceará (UFC). Fortaleza/ CE. Maternidade Escola Assis Chateaubriand (MEAC). Telefone 85326176 29. E-mail maiaramascarenhas@hotmail.com.

${ }^{2}$ Assistente social na Pró-Reitoria de Assuntos da Universidade Federal do Ceará, Mestre em Educação e Doutora em Ciências Sociais. E-mail georgiapgs@hotmail.com.

${ }^{3}$ Assistente social da Universidade Federal do Ceará e da Prefeitura Municipal de Fortaleza, mestre em Políticas Públicas pela Universidade Estadual do Ceará - UECE. E-mail anakarlabbz@yahoo.com.br. ${ }^{4}$ Assistente social da Maternidade Escola Assis Chateaubriand - UFC, especialista em Atenção Hospitalar na área de concentração Saúde da Mulher e da Criança pela Universidade Federal do Ceará (UFC). E-mail edileneribeiroas@gmail.com.
}

Serv. Soc. \& Saúde, Campinas, SP v. 12, n. 2 (16), p. 221-236, jul./dez. 2013 ISSN 1676-6806 


\section{INTRODUÇÃO}

O Brasil teve sua colonização marcada pelo patriarcalismo e pelas diversas formas de desigualdades entre classes, que negligenciaram a criança e o adolescente como sujeitos sociais. Esse patriarcalismo familiar, na verdade, representou, segundo Pinheiro (2006), uma centralidade de comando no homem, chefe da família, pois esse era o senhor das terras, dos escravos, enfim, do patrimônio. Logo, toda a vida social era subordinada ao patriarca da família formando uma relação de subordinação e dependência. Nesse contexto, a criança sempre esteve subordinada ao adulto, numa relação de desigualdade e hierarquia, sendo submetida a violências físicas como forma de castigo e repressão, muitas vezes sob a justificativa de ser esse um método educativo.

Pinheiro (2006), então, infere que as desigualdades acontecem ao longo da construção da sociedade brasileira contrapondo-se à ideia de universalidade de direitos, subsidiando, ao mesmo tempo, a naturalização da pobreza e a banalização da injustiça. Um exemplo disso foi a Roda dos Expostos, ligada às Santas Casas de Misericórdia uma forma emblemática de "proteção social" à criança, criada em 1738, no Rio de Janeiro, com o intuito de acolher crianças que eram abandonadas, nascidas de pessoas pobres ou tidas fora do casamento.

Historicamente, essa forma de "proteção" esteve diretamente associada a uma relação de "favor", pois quando a criança não poderia ser criada por quem realmente tinha responsabilidade sobre ela, essa missão era transferida para uma pessoa que o faria como um ato de "caridade".

O Código de Menores de 1927 foi a primeira lei destinada à criança e ao adolescente. No entanto, essa legislação está voltada à parcela pobre da população, associando-se o termo "menor" a uma característica de inferioridade, com um sentido pejorativo. Sobre esse Código, Pinheiro (2006) afirma que “'Menor' é, portanto, um conceito institucionalizado a partir de uma lei, o Código de Menores, e que institui exclusões e práticas, por meio da criação de instituições e da formulação de políticas públicas" (ibid., p.70).

Atualmente, os locais para onde as crianças são encaminhadas quando por algum motivo, não têm condições de permanecer no convívio da família natural ou ampliada são as Unidades de Acolhimento. Algumas dessas, mantidas pela iniciativa privada e Serv. Soc. \& Saúde, Campinas, SP v. 12, n. 2 (16), p. 221-236, jul./dez. 2013 ISSN 1676-6806 
outras pelo Poder Público, são conhecidas também como Abrigos.

As Unidades de Acolhimento estão regulamentadas no Capítulo II da Lei n. ${ }^{\circ}$ 8.069, de 13 de julho de 1990, que dispõe sobre o Estatuto da Criança e do Adolescente (ECA). Legitimando os direitos individuais, políticos e sociais, que até então eram exclusividade dos adultos, o ECA é fruto das intensificações das lutas pela democratização do país e pela garantia dos direitos sociais, a partir da formulação da nova Constituição Federal de 1988. Logo, como destaca Dalton (2008), esse novo ordenamento jurídico é o reconhecimento, por parte do Estado, da defesa e da garantia dos direitos humanos.

Desse modo, esse Estatuto reforça o que já havia na Constituição Federal de 1988, colocando como responsabilidade da família, da comunidade, da sociedade em geral e do poder público, assegurar a efetivação dos direitos da criança e do adolescente, respeitando a condição de pessoas em desenvolvimento. Essa condição peculiar, Pinheiro (2006) afirma que deve ser compreendida em relação às necessidades que ocorrem do processo de maturação física e psicológica a que estão submetidos crianças e adolescentes, bem como a sua inserção na trama de relações e práticas sociais mediante socialização.

Nessa perspectiva, não é possível analisar a situação da infância no Brasil desvinculada das discussões sobre a família, que, como pode ser percebido em determinados artigos da Constituição Federal Brasileira e do ECA, é basilar na proteção e na garantia dos direitos à criança e ao adolescente. Por esse viés, a família é tida como ponto de confluência da realidade dos grupos considerados mais vulneráveis: criança e adolescente, idosos, mulheres etc.

Validamente, devemos perceber a família brasileira considerando a formação sócio-histórica dessa sociedade, a miscigenação da população e a interferência de diversas culturas desde o período da colonização do país. Assim, não se deve pensar em uma família regular ou padrão, e sim, numa família plural, respeitando a diversidade cultural. Neder (2004) contribui a respeito desse assunto afirmando "que não existe, histórica e antropologicamente falando, um modelo-padrão de organização familiar" (ibid., p. 28)

Historicamente, foi construído um modelo padrão na sociedade brasileira, no qual Osterne (2001) afirma que "a imagem mais instantânea que se tem de uma família é aquela onde aparece pai, mãe e filhos vivendo numa mesma casa [...]. Essa imagem Serv. Soc. \& Saúde, Campinas, SP v. 12, n. 2 (16), p. 221-236, jul./dez. 2013 ISSN 1676-6806 
corresponde a um modelo, o tradicional modelo da família nuclear burguesa" (ibid., p. $51-52)$.

Portanto, essas concepções historicamente atribuídas ao conceito de família interferem, ainda hoje, na forma de pensar da sociedade e do Estado sobre essa categoria. Neder (2004) comenta sobre o quadro atual das famílias brasileiras que:

Primeiramente, deve-se levar em conta que muitas das percepções construídas historicamente pelas elites persistem de forma hegemônica. Em segundo lugar, observa-se que a formulação mais simpática às classes populares que trata a organização familiar ainda está presa nas malhas de um enfoque que enfatiza a relação pobreza/família irregular (NEDER, 2004, p. 42).

Em meio às conquistas de direitos da criança e do adolescente e da busca pela efetivação desses, sem desvincular das discussões sobre a importância da família, verificamos uma importante situação através do levantamento dos dados dos relatórios sociais do ano de 2012, do Serviço Social da Maternidade Escola Assis Chateaubriand (MEAC), em Fortaleza (CE) qual seja: dos 43 relatórios sociais encaminhados ao Conselho Tutelar, sete desses casos tiveram como desfecho a decisão pelo acolhimento institucional dos recém-nascidos, sendo encaminhados para quatro Unidades de Acolhimento, uma vez que havia como principais motivos para tais decisões a situação de drogadição dos pais ou abandono das crianças por seus genitores. Desse modo, elas não poderiam permanecer na convivência familiar ou comunitária. Assim, questionamos qual a situação atual dessas crianças e como ocorre a continuidade desses casos, a fim de que sejam realmente garantidos os seus direitos.

A equipe do Serviço Social da MEAC acompanha as famílias dos recémnascidos, verificando as situações de vulnerabilidade social e buscando alternativas por meio dos encaminhamentos para a rede socioassistencial, notificando ao Conselho Tutelar os casos previstos na legislação.

Dessa forma, o presente estudo justificou-se pela relevância de investigarmos a garantia dos dispositivos legais que asseguram os direitos das crianças ${ }^{5}$ encaminhadas pelo Conselho Tutelar ao Acolhimento Institucional, no ano de 2012, a partir da experiência na Maternidade Escola Assis Chateaubriand (MEAC) em Fortaleza (CE).

\footnotetext{
${ }^{5}$ Ressaltamos que a denominação criança está sendo utilizada de acordo com o que previsto pelo Estatuto da Criança e do Adolescente, considerando criança como pessoa na faixa etária de zero a doze anos incompletos.

Serv. Soc. \& Saúde, Campinas, SP v. 12, n. 2 (16), p. 221-236, jul./dez. 2013 ISSN 1676-6806
} 
Tal indagação é motivada por percebermos que, na maioria das vezes, a equipe do Serviço Social da MEAC que encaminhou o caso não recebe retornos sobre os procedimentos adotados pelos Conselhos Tutelares, órgão encarregado pela sociedade de zelar pelo cumprimento dos direitos da criança e do adolescente, ficando sem respostas sobre a real efetivação desses direitos.

\section{Procedimentos Metodológicos da Pesquisa}

A pesquisa foi realizada em três Unidades de Acolhimento de Fortaleza (CE) para as quais os recém-nascidos na MEAC foram encaminhados no ano de 2012. Vale ressaltar que não foi possível entrevistar o profissional de uma das Unidades, devido a dificuldades relacionadas à burocracia para autorização da pesquisa pelo órgão responsável desse local.

Salientamos que este estudo foi realizado como Trabalho de Conclusão de Curso da Residência Multiprofissional em Atenção Hospitalar na área de concentração Saúde da Mulher e da Criança.

Os sujeitos da pesquisa foram os assistentes sociais dessas unidades de acolhimento que acompanharam as situações dessas crianças, por acreditarmos que possam nos responder sobre os encaminhamentos realizados e sobre a atual situação sócio jurídica das mesmas.

Este trabalho é de natureza qualitativa descritiva, pois busca ultrapassar apenas os dados numéricos, significando-os. Martinelli (1999) afirma que nesse tipo de pesquisa não desconectamos o sujeito da sua estrutura, procurando entender os fatos, a partir da interpretação que faz dos mesmos em sua vivência cotidiana.

$\mathrm{Na}$ pesquisa de campo, utilizamos como técnica de coleta de dados a entrevista semiestruturada e a análise documental. A primeira técnica trouxe um roteiro de questões previamente formulado, com perguntas abertas, possibilitando aos entrevistados discorrerem livremente sobre a temática. Para a melhor apreensão dos dados, foi utilizado um gravador durante as entrevistas, conforme autorização prévia dos entrevistados. Além disso, as entrevistas foram realizadas mediante a assinatura do Termo de Consentimento Livre e Esclarecido - TCLE, conforme Resolução $\mathrm{n}^{\mathrm{o}}$ 196/1996, que regulamenta a pesquisa com seres humanos.

A outra técnica de coleta de dados foi a análise documental. Coletamos Serv. Soc. \& Saúde, Campinas, SP v. 12, n. 2 (16), p. 221-236, jul./dez. 2013 ISSN 1676-6806 
informações dos relatórios sociais, do Serviço Social da MEAC, para complementar e validar as informações obtidas. A análise dos dados e a interpretação dos resultados obtidos serão avaliadas a partir das concepções teóricas dos autores adotados, com a divisão por categorias de acordo com o que identificamos que surge de relevante. Com efeito, esta pesquisa não pretende apresentar respostas definitivas, mas um novo olhar sobre a realidade estudada, que pode ser modificado devido ao próprio movimento histórico-dialético da sociedade. Assim, como Araújo (2003) afirma, todo o conhecimento elaborado traz em si uma esfera desconhecida, pois, ao mesmo tempo em que ele amplia as possibilidades de percepção do real, este apresenta novos elementos, que exigem novos olhares e novas elaborações teóricas.

Ressaltamos que esta pesquisa foi submetida ao Comitê de Ética e Pesquisa da Maternidade Escola Assis Chateaubriand com o parecer de aprovação $n^{\circ} 375.343$. Quanto aos princípios éticos, foram respeitados, garantindo-se a veracidade dos resultados obtidos e o sigilo das identidades.

\section{Institucionalização, manutenção de vínculos e destituição do poder familiar: decisão sobre o futuro das crianças}

$\mathrm{Na}$ pesquisa realizada, constatamos que das sete crianças encaminhadas, em 2012, da MEAC ao Acolhimento Institucional, apenas uma não estava mais institucionalizada, pois já havia retornado para a família. Entre as cinco que permaneciam acolhidas: uma estava ainda em situação de manutenção de vínculos com a família ampliada; para as outras, a equipe já havia sugerido nos Relatórios Sociais encaminhados ao Juizado da Infância e da Juventude a destituição do poder familiar e aguardavam uma resposta. Ressaltamos que não conseguimos realizar a pesquisa em uma das Unidades de Acolhimento, assim não sabemos a atual situação desta criança.

O período de acolhimento dessas crianças que ainda permanecem na Instituição era, em média, de um ano, dado que deve ser considerado analisando o período da realização da pesquisa, o ano seguinte ao acolhimento. Assim, nos questionamos sobre o futuro dessas crianças, pois os relatos dos profissionais são bastante enfáticos quando relatam que uma das grandes dificuldades enfrentadas é a morosidade dos processos judiciais. Vejamos:

Serv. Soc. \& Saúde, Campinas, SP v. 12, n. 2 (16), p. 221-236, jul./dez. 2013 ISSN 1676-6806 
[...] Todavia, existe um descaso muito grande, por quê? Por mês é julgado uma ação de destituição do poder familiar, envolvendo crianças e adolescentes, ou uma reintegração familiar de todos os abrigos de Fortaleza, que são mais de 20, enquanto que, por exemplo, no caso das ações envolvendo adolescentes em conflito com a Lei são julgadas centenas, duzentas, trezentas ações, porque tem a questão dos 45 dias e tudo mais. Então, o que acontece, existe uma prioridade muito grande do poder judiciário das varas estarem julgando os casos envolvendo o conflito com a Lei, e os casos envolvendo acolhimento institucional e reintegração familiar é visto como segunda grandeza, não é tão importante, então é deixado de lado. Então, isso faz com que haja, por exemplo, destituição do poder familiar pedida a mais de cinco anos e que não foi concretizada e que a criança tá lá no abrigo. (Assistente Social 2)

Então, eu acho que essa morosidade acaba muito, deixa muito a desejar e acaba com a infância dessas crianças porque elas ficam aqui institucionalizadas só aguardando e a gente vendo...

(Assistente Social 3).

Nesse aspecto, Fávero (2007) aponta que as pesquisas relacionadas às práticas judiciárias ainda não recebem atenção suficiente dos pesquisadores, tal fato reforça uma tendência institucional de manter-se apartada da realidade social, dificultando uma mudança necessária de mentalidade de muitos dos seus agentes, na direção da plena implementação das disposições contidas no Estatuto da Criança e do Adolescente.

Vale salientar que, com a demora do período de institucionalização dessa criança, diminuem as possibilidades de uma adoção, caso seja decidido pela destituição do poder familiar. De acordo com os dados do Conselho Nacional de Justiça (2012), a maior dificuldade para que as 5.284 crianças e adolescentes, que estão no Cadastro Nacional de Adoção, consigam uma nova família é o perfil exigido pelos pretendentes à adoção, pois expressiva maioria pretende adotar crianças do sexo feminino, de cor branca, com idade inferior a três anos, não integrantes de grupos de irmãos e que sejam saudáveis. Os profissionais entrevistados também relataram esta dificuldade:

Tem uma criança que chegou aqui com três meses, que a mãe tá institucionalizada também, e ela ainda tá aqui, ela já fez quatro anos e aí ninguém decide o caso dela. A gente vai pra audiência e não acontece, quando acontece não se decide, então fica complicado. A criança tá aqui há muito tempo só esperando que a vida dela seja decidida. Isso muitas vezes não depende do nosso trabalho. [...] Até sai do perfil, às vezes ela vai crescendo, crescendo, crescendo, completa sete, oito anos e infelizmente não é mais o perfil que muitos desejam, o perfil dos casais, das pessoas que estão no cadastro. Aí fica mais difícil até pra uma adoção.

(Assistente Social 3) 
O acolhimento institucional é previsto pelo Estatuto da Criança e do Adolescente como uma forma de medida protetiva, aplicada quando a criança e o adolescente têm algum de seus direitos violados, devendo ser uma medida excepcional e provisória. Ainda de acordo com o Estatuto (BRASIL, 1990), o acolhimento institucional e o acolhimento familiar são medidas provisórias e excepcionais, utilizáveis como forma de transição para reintegração familiar ou, não sendo essa possível, para colocação em família substituta, não implicando privação de liberdade.

O ECA também regulamenta no artigo $92^{\circ}$ os princípios que serão adotados pelas entidades que desenvolvem programas de acolhimento, priorizando a convivência familiar e comunitária. A implantação do Estatuto colaborou para modificações efetivas no que tange às instituições de assistência e à sua configuração como um todo, concebendo-as como espaço de socialização e de desenvolvimento (SIQUEIRA; DELL'AGLIO, 2006).

Além disso, no segundo parágrafo do artigo $19^{\circ}$ do ECA (BRASIL, 1990), é estabelecido o tempo máximo de permanência dessas crianças nas instituições de acolhimento: a permanência da criança e do adolescente em programa de acolhimento institucional não se prolongará por mais de 2 (dois) anos, salvo comprovada necessidade que atenda ao seu superior interesse, devidamente fundamentada pela autoridade judiciária. Outro artigo violado diante do relato dos profissionais, conforme abaixo:

O M. chegou aqui com meses, já tem um ano, a gente pediu a destituição com seis meses e já está em processo de destituição. A criança já tá com um ano, ainda tá correndo o processo então pode ser que seja com dois anos ou três.

(Assistente Social 1)

Acrescenta-se que essa legislação também assegura que a situação dessas crianças seja avaliada a cada dois meses, fato que, mesmo sendo instituído legalmente, esbarra numa dificuldade estrutural das Unidades de Acolhimento, que muitas vezes não têm uma equipe técnica suficiente para acompanhar a quantidade de casos da instituição, como revela a entrevista a seguir:

Aí essas dificuldades somam-se as dificuldades da equipe técnica, porque são 38 casos, então são 38 famílias, 38 situações, e pelas normas e diretrizes do acolhimento institucional, a cada 20 crianças você tem que ter uma equipe de um assistente social e um psicólogo, a gente tá com 38 aqui com um assistente social e um psicólogo. Então, 
nosso trabalho aqui, é um trabalho que fica reduzido, muito pouco. Tô com uma dificuldade estrutural, eu tô sem a minha sala, tô tendo que fazer um jogo de cintura muito grande.

(Assistente Social 2).

Constatamos, então, a distância entre a legislação e sua efetivação prática, pois vale ressaltar que muitos desses artigos mencionados, contidos no ECA, foram incluídos pela Lei $\mathrm{n}^{\circ} 12.010$, de 03 de agosto de 2009 , com o intuito de prevenir o afastamento do convívio familiar e comunitário, desburocratizar o processo de adoção e evitar o prolongamento da permanência em abrigos.

Contudo, a situação dessas crianças nos traz uma reflexão sobre a infância perdida nessas instituições. Percebemos que, mesmo com as garantias legais, as quais começaram desde o século $\mathrm{XX}$, com as primeiras legislações voltadas para esse segmento da população, ainda percebemos situações de descaso, negligenciando-se direitos, fato percebido historicamente com as crianças e os adolescentes.

Portanto, os longos períodos de institucionalização causados ou pela dificuldade de condições da família para receber as crianças ou pela morosidade da justiça na decisão dos casos de destituição do poder familiar, comprometem o futuro dessas crianças que têm o direito à convivência familiar e comunitária, parcialmente, cerceado quando se encontram numa instituição de acolhimento.

\subsection{A situação das famílias e das crianças no contexto das políticas neoliberais}

Percebemos nas legislações brasileiras a importância da família para o desenvolvimento humano. Nas políticas sociais, a Constituição Federal Brasileira define a família como base da sociedade e com especial proteção do Estado; o Estatuto da Criança e do Adolescente também afirma como dever da família, da comunidade, da sociedade em geral e do poder público assegurar às crianças e aos adolescentes, com absoluta prioridade, a efetivação dos direitos referentes à vida, à saúde, à alimentação, à educação, ao esporte, ao lazer, à profissionalização, à cultura, à dignidade, ao respeito, à liberdade e à convivência familiar e comunitária.

Da mesma forma, observamos também no discurso dos entrevistados o foco dado à família e à tentativa de retorno das crianças para o seio familiar, buscando na rede socioassistencial as alternativas para as mudanças das condições que geraram o 
acolhimento institucional dessas crianças. Sobre isso, destaca-se o seguinte depoimento de um dos profissionais entrevistados:

Esse é um trabalho que a gente tenta fazer, procura fazer junto com a família, identificando as vulnerabilidades e trabalhando em cima delas com os encaminhamentos que forem necessários pra isso.

(Assistente Social 3).

Apreendemos ainda a centralidade da família, quando o ECA garante em seu artigo $19^{\circ}$ o direito da criança ou adolescente de ser criado e educado no seio da sua família, excepcionalmente, em família substituta (BRASIL, 1990). Por isso a tentativa de manutenção de vínculos com família natural e a ampliada é o primeiro procedimento a ser realizado em todas as unidades de acolhimento visitadas, conforme ressaltam os sujeitos da pesquisa a seguir:

A gente vai fazer a busca da família. A gente vai tentar a família ampliada, a família mesmo: pai e mãe, e a família ampliada, para ver se a gente traz a família pra cá pra fazer a manutenção do vínculo. (Assistente Social 1)

Primeiramente, a gente vê como se encontra o núcleo familiar, quem era parte da composição daquela família, pai mãe, tio... quem eram os residentes e depois quem tinha mais algum tipo de afinidade com as crianças.

(Assistente Social 2)

Como preconiza o Estatuto a gente tem que trabalhar com a família de origem e aí a gente realiza... primeiro a gente vai em busca dessa família, se essa família não veio visitar a criança, a gente vai através dos contatos que tivermos nos relatórios que veio com a criança e vai fazer, como a gente diz, um trabalho de investigação inicialmente. (Assistente Social 3)

Portanto, a família é chamada a assumir os cuidados com essas crianças. Mioto (2004) afirma que "a família tem sido cada vez mais valorizada no âmbito das propostas de enfrentamento às diferentes manifestações dos problemas relacionados à infância, através de programas geralmente denominados de orientação e apoio sociofamiliar" (ibid., p. 43). No entanto, a relação entre Estado e família desenvolve-se de maneira contraditória, uma vez que as políticas voltadas para a família são residuais, compensatórias e focalistas, não dando conta da atual realidade das famílias brasileiras. Assim, há uma dificuldade de encontrar respostas aos encaminhamentos, como também resolução das situações encontradas, tal como enfatiza um dos assistentes sociais das unidades de acolhimento pesquisadas: 
Quando a gente realiza todo esse trabalho que foi feito de atendimento, de visita, de encaminhamento e a gente verifica que não houve possibilidade da família superar aquela condição que gerou o acolhimento; que a gente sabe que é muito complicado não só pela família, mas por toda uma condição que envolve por trás de políticas públicas, que infelizmente não alcançam toda essa demanda da família. A gente sabe que a rede socioassistencial ainda tem muito a caminhar pra atender as demandas da família e, é por conta disso, quando a gente verifica que não houve possibilidade de atender, de acabar com essa vulnerabilidade que gerou o acolhimento. Aí a gente verifica que não tem mais porque continuar com esse trabalho de manutenção do vínculo.

(Assistente Social 3)

Diante dessa dificuldade de articulação com a rede socioassistencial, mesmo que o ECA assegure no artigo $23^{\circ}$ que a falta ou carência de recursos materiais não constitui motivo suficiente para a perda ou a suspensão do poder familiar (BRASIL, 1990), a situação de pobreza perpassa por outras expressões da questão social que, pela ausência de suporte do Estado com vistas a mudar a condição social da família, gera um motivo para a equipe das unidades de acolhimentos solicitar a destituição do poder familiar.

Vejamos uma situação exemplificada em uma das entrevistas coletadas para este estudo:

Eu tenho um caso aqui que praticamente são todas as expressões da questão social num só caso: que é os pais do F.J. Eles são catadores de latinha, eles têm interesse na criança, mas os dois são usuários de álcool, os dois têm várias doenças diferentes em decorrência de falta de alimentação, de uma boa alimentação, em decorrência da situação de rua, de higiene, várias doenças, moram... Não têm moradia porque a casa deles pegou fogo, então eles moram num local abandonado. Então, aí vai moradia, aí vai alcoolismo, uso de drogas, aí vai pobreza extrema. Então esse, digamos assim, é o grande problema da gente, que é um problema estrutural. Como conseguir encaminhar isso para a rede socioassistencial? Ela foi pro posto de saúde que eu indiquei e, no outro dia, ele veio me dizer aqui que eles ficaram o dia inteiro lá e não receberam atendimento. Como é que faz em relação a isso? (Assistente Social 3)

Entendemos, então, que a família, muitas vezes, passa a assumir atribuições anteriormente delegadas ao Estado. Lembremos que, na década de 1990, houve uma expansão da partilha da responsabilidade entre o Estado, a sociedade civil e a iniciativa privada, a qual é denominada por Carvalho (2002) de Welfare Mix, pois os países latino-americanos, em especial o Brasil, não viveram exatamente um Estado de bemestar social, havendo sempre esse compartilhamento de responsabilidades. Nesse sentido, a ausência ou inoperância do Estado penaliza a família por seu próprio Serv. Soc. \& Saúde, Campinas, SP v. 12, n. 2 (16), p. 221-236, jul./dez. 2013 ISSN 1676-6806 
sofrimento, pela falta de condições dignas de sobrevivência.

Todavia, vale esclarecer que não pretendemos questionar ou minimizar a importância da família nos cuidados com as crianças, considerando a relevância da proteção e formação de vínculos afetivos. Porém, como Carvalho (2002) aponta, é fundamental entender que a revalorização da família não pode significar um recuo da proteção social destinada pelo Estado.

Diante desse contexto, avaliamos que as políticas sociais também não conseguem atender o grande número de pais e familiares dessas crianças institucionalizadas que fazem uso abusivo de substâncias lícitas (álcool) e ilícitas. Os dados coletados no Serviço Social da MEAC no ano de 2012 indicam que dos 43 casos encaminhados ao Conselho Tutelar, 26 estão relacionados à situação de drogadição dos genitores. Identificamos tal situação também nas falas dos profissionais:

Em relação aos pais, eu acho que $90 \%$ das crianças - a gente tem hoje 90 crianças - 90\% delas, um dos genitores é dependente químico. Então, para isso, a gente não tem uma rede que trabalhe. A gente sabe que a dependência química é difícil a pessoa sair disso, deixar de ser um dependente. É uma doença. A gente sabe que é saúde pública. E não é assim.

(Assistente Social 1)

No entanto, diante da precariedade da rede socioassistencial, essas crianças ficam à mercê da organização dessas famílias que não têm respostas das políticas públicas. $\mathrm{O}$ Estado não garante os recursos mínimos necessários para o desenvolvimento saudável da criança nessa família, já que o próprio ECA indica em seu artigo $19^{\circ}$, que a criança tem direito de viver em ambiente livre da presença de pessoas dependentes de substâncias entorpecentes (BRASIL, 1990). Observamos na fala de um dos profissionais as dificuldades de acesso das famílias a condições dignas de sobrevivência e a espera das crianças, em instituições de acolhimento, de condições de retorno ao convívio familiar:

O trabalho do Serviço Social é dar viabilidade para que essa família se estruture para receber a criança novamente. Encaminha para as várias... Para a rede socioassistencial, em relação a habitação, a saúde... A gente encaminha pra ver se ela consegue se reestabelecer, se reestruturar pra receber a criança. Quando isso não tem como acontecer e quando é um usuário de drogas, quando não tem uma habitação, que isso demora, a gente tem que continuar fazendo essa manutenção, possibilitando que ele venha visitar a criança pra não 
perder o vínculo até ele puder...

(Assistente Social 1)

Assim, verificamos um Estado omisso, responsabilizando cada vez mais a família, tal como pressupõe as características das políticas neoliberais ${ }^{6}$. Mioto (2004, p. 47) alega que "pede-se à família o exercício de um papel substitutivo em relação ao sistema de direitos sociais".

Observamos que as legislações preveem políticas de atendimento que garantam proteção integral à criança, no entanto, assim como Fávero (2007, p. 111) destaca, "as políticas é que não vêm sendo implementadas de forma a atender às disposições legais".

Outro aspecto que devemos ressaltar refere-se à idealização de uma família organizada ou "estruturada", que está muitas vezes no imaginário coletivo. Precisamos compreendê-la como grupo social, cujos movimentos de organização-desorganizaçãoreorganização mantêm estreita relação com o contexto sociocultural. Identificamos nas falas essas diversas composições familiares:

O nosso perfil aqui, como é todas as faixas etárias, a gente recebe de zero a dezoito anos, então a gente tem todo tipo de caso possível e imaginável em relação a família, de estruturas familiares diferenciadas.

(Assistente Social 2)

Apreendemos um cenário adverso para a garantia dos direitos dessas crianças, com a falta de políticas públicas eficazes para assegurar a permanência desse segmento da população no convívio familiar e comunitário. Assim, os fatores apresentados acabam gerando um maior período de institucionalização das crianças, com situações que dificultam a manutenção do vínculo com essas famílias, gerando até o afastamento definitivo dos vínculos familiares com a destituição do poder familiar.

\section{CONSIDERAÇÕES FINAIS}

Percebemos diante da realidade apresentada que a garantia dos direitos dessas crianças que se encontram em unidades de acolhimento perpassa por vários problemas estruturais da sociedade, que vão desde a ineficácia das políticas sociais até os

\footnotetext{
${ }^{6}$ A tendência geral tem sido a de restrição e redução de direitos, sob o argumento da crise fiscal do Estado, transformando as políticas sociais [...] em ações pontuais e compensatórias direcionadas para os efeitos mais perversos da crise. As possibilidades preventivas e até eventualmente redistributivas tornamse mais limitadas, prevalecendo o já referido trinômio articulado do ideário neoliberal para as políticas sociais, qual seja: a privatização, a focalização e a descentralização (BEHRING; BOSCHETTI, 2007). Serv. Soc. \& Saúde, Campinas, SP v. 12, n. 2 (16), p. 221-236, jul./dez. 2013 ISSN 1676-6806
} 
problemas no poder judiciário, na procrastinação dos processos.

As famílias, mesmo diante das diversas refrações da questão social, são o foco das ações voltadas para as crianças e os adolescentes, sendo percebidas como a solução para esses casos. No entanto, as políticas públicas, de modo geral, não têm contemplado as mudanças na concepção de família, as transformações nos papéis de seus membros, tampouco os diversos arranjos familiares hoje existentes.

Sem dúvidas, a família tem um papel fundamental na situação das crianças acolhidas institucionalmente, no entanto, percebemos uma transferência da responsabilidade do Estado para a família, que, através de políticas fragmentadas, reforça soluções cada vez mais residuais aos problemas relacionadas à família, sem oferecer-lhes suporte para enfrentar as situações de vulnerabilidade.

São esses fatores que geram, algumas vezes, o acolhimento institucional e a impossibilidade de manutenção do vínculo. Portanto, as dificuldades enfrentadas pelas famílias perante um Estado com políticas neoliberais são fundamentais na avaliação das condições para permanecerem com as crianças em seu convívio.

Outro fator decisivo para a situação dessas crianças é a distância entre as legislações e as realidades encontradas nas unidades de acolhimento pesquisadas. Enquanto o Estatuto da Criança e do Adolescente trouxe várias garantias legais para esse segmento da população, o poder judiciário não o acompanhou, na prática, com a efetivação de tais direitos. Apreendemos situações que vão de encontro com o previsto no ECA, nas quais os direitos das crianças estão sendo violados e o futuro delas está comprometido numa unidade de acolhimento, que mesmo com boas condições de sobrevivência, não garante as mesmas condições que uma família, natural ou substituta, garantiria.

\section{REFERÊNCIAS}

ARAÚJO, L. B. C. A questão do método em Marx e Lukács: o desafio da reprodução ideal de um processo real. In: Trabalho, sociabilidade e educação: uma crítica à ordem do capital. Fortaleza: Editora UFC, 2003.

BEHRING, E. R.; BOSCHETTI, I. Política Social: Fundamentos e História. $3^{\text {a }}$ ed. Biblioteca Básica do Serviço Social, v.2, São Paulo: Cortez, 2007. 
BRASIL. Estatuto da Criança e do Adolescente. Lei Federal 8.069/1990.

BRASIL. Conselho Nacional de Justiça. Cadastros Infância e Juventude. 2012. Disponível em: $\quad<\quad$ http://www.cnj.jus.br/images/programas/relatoriosanuais/cadastro_adocao.pdf.

BRASIL. Constituição da República Federativa do Brasil de 1988. Disponível em: <

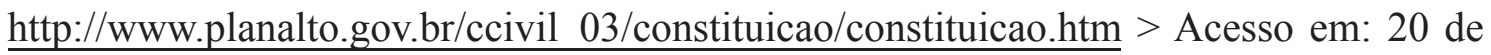
março de 2013.

CARVALHO, M. do C. B. de. O lugar da família na política social. In: CARVALHO, M. do C. B. de. (Orgs.) A família contemporânea em debate. São Paulo: EDUC / Cortez, 2002.

DALTON, A. M. Os Direitos Humanos à luz do Código de Ética do Serviço Social e do Estatuto da Criança e do Adolescente: Afinal, o que estamos defendendo? 2008. 114f. Dissertação (Mestrado em Serviço Social) - Pontifícia Universidade Católica do Rio de Janeiro, Rio de Janeiro, 2008.

FAVERO, E. T. Questão social e perda do poder familiar. São Paulo: Veras Editora, 2007.

LUDWIG, A. C. W. Fundamentos e prática de Metodologia Científica. Petrópolis, RJ: Vozes, 2009.

MARTINELli, M. L. Pesquisa qualitativa: um instigante desafio. São Paulo: Vera Editora, 1999.

MIOTO, R. C. T. Novas propostas e velhos princípios: a assistência às famílias no contexto de programas de orientação e apoio sociofamiliar. In: SALES, M. A.; MATOS, M. C.; LEAL, M. C. (orgs). Política Social, família e juventude: uma questão de direitos. São Paulo: Cortez, 2004.

NEDER, G. Ajustando o foco das lentes: um novo olhar sobre a organização das famílias no Brasil. In: KALOUSTIAN, S. M. Família brasileira: a base de tudo. 6. Ed. São Paulo: Cortez; Brasília, DF: UNICEF, 2004.

NETO, O. C. O trabalho de campo como descoberta e criação. In: MINAYO, M. C. de S. Pesquisa Social: Teoria, método e criatividade. São Paulo: Vozes, 2007. OSTERNE, M. do S. F. Família, pobreza e gênero: o lugar da dominação masculina. Fortaleza: EDUECE, 2011. 266 p.

PINHEIRO, A. A. A. Criança e adolescente no Brasil: porque o abismo entre a lei e a realidade. Fortaleza: Editora UFC, 2006..

Serv. Soc. \& Saúde, Campinas, SP v. 12, n. 2 (16), p. 221-236, jul./dez. 2013 ISSN 1676-6806 
SIQUEIRA, A. C.; DELL'AGLIO, D. D. O impacto da institucionalização na infância e adolescência: uma revisão de literatura. Psicologia \& Sociedade, $n^{0}$ 18, 2006, p. 71-80. 